\title{
Angiotensin II-Induced Renal Vasodilation Mediated by Cytochrome P-450 Arachidonic Acid Metabolites
}

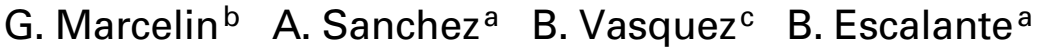 \\ a Departments of Molecular Biomedicine and ${ }^{\mathrm{b}}$ Pharmacology, Centro de Investigación y de Estudios Avanzados \\ del IPN, and 'Division of Investigation, Escuela Nacional de Estudios Profesionales Iztacala UNAM, Tlalnepantla, \\ Edo México, México
}

\section{Key Words}

Angiotensin II - Cytochrome $\mathrm{P}-450$ arachidonic acid metabolites $\cdot \mathrm{AT}_{2}$ receptors

\begin{abstract}
Objective: Activation of $\mathrm{AT}_{2}$ angiotensin II receptor release cytochrome P-450 arachidonic acid metabolites (CYP-AA). The presence of the $\mathrm{AT}_{2}$ receptor and its ability to mediate renal vasodilation through CYP-AA metabolites were evaluated. Methods: Vascular response to angiotensin II in the isolated perfused kidney of the rat was evaluated in the absence and presence of angiotensin II $A T_{1}$ and $A T_{2}$ receptor blockers. Results: Blockade of the $A T_{1}$ receptor unmasked a vasodilatory response that was inhibited by $\mathrm{AT}_{2}$ receptor blockade and AA metabolism. Conclusion: The findings indicate that blockade of the $A T_{1}$ angiotensin II receptor, activation of $A T_{2}$ receptors, releases CYP-AA metabolites that induce renal vasodilation.
\end{abstract}

Copyright @ 2001 S. Karger AG, Basel

\section{Introduction}

The kidney is an important target organ for angiotensin II (AngII), which plays a critical role in the regulation of kidney function. Two major isoforms of AngII receptors, type $1\left(\mathrm{AT}_{1}\right)$ and type $2\left(\mathrm{AT}_{2}\right)$, have been defined on the basis of their ligand selectivity. Most of the known effects of AngII are attributable to $\mathrm{AT}_{1}$ receptors. However, it has recently been demonstrated that vascular tissue expresses a small but significant amount of $\mathrm{AT}_{2}$ receptors as well [1]. Moreover, $\mathrm{AT}_{2}$ receptors are abundantly and widely expressed in fetal tissues and this predominance of $\mathrm{AT}_{2}$ receptors is reversed during development [1]. Activation of renal $\mathrm{AT}_{2}$ receptors has recently been reported to regulate pressure natriuresis, causing vasodilation in the preglomerular afferent arteriole, stimulating renal nitric oxide production [2]. AngII stimulates phospholipase $\mathrm{A}_{2}$ and releases arachidonic acid (AA) in various tissues including renal cells. This effect has been associated with an increased production of cytochrome P-450dependent AA metabolites (CYP-AA). Moreover, AngII increases the production of the CYP-AA metabolites and epoxyeicosatrienoic acids (EETs) through the stimulation of $\mathrm{AT}_{2}$ receptors [3]. The EETs may be the endotheliumderived hyperpolarizing factor that plays an important

B. Escalante, Departamento de Biomedicina Molecular

Centro de Investigación y de Estudios Avanzados del IPN

Avenida Instituto Politécnico Nacional 2508, México DF, CP 07300 (México)

Tel. +52 57477000 , ext. 5458, Fax +5257477134

E-Mail bescalan@mail.cinvestav.mx
Fax +41613061234

E-Mail karger@karger.ch

www. karger.com
1011-7571/01/0101-0011\$17.50/0

Accessible online at:

www. karger.com/journals/mpp 


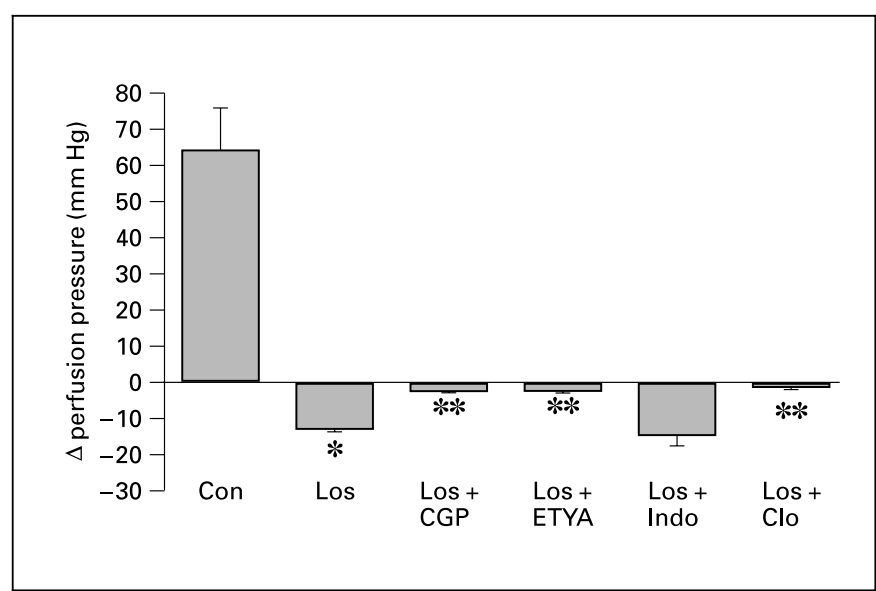

Fig. 1. Effect of AA metabolism inhibitors on AngII-induced vasodilation. Isolated perfused kidneys of rats were stimulated with $16 \mathrm{ng}$ of AngII in the absence of inhibitors (Con) or in the presence of Losartan (Los), Losartan and CGP (Los + CGP), Losartan and AA antagonist (Los + ETYA), Losartan and indomethacin (Los + Indo) or Losartan and clotrimazole ( $\mathrm{Los}+\mathrm{Clo})$. Each bar represents the mean \pm SE of 5 different experiments. $* \mathrm{p}<0.05$ compared with Con and ** compared with Los.

role in the control of glomerular hemodynamics [4]. Thus the possibility arises that AngII, through activation of $\mathrm{AT}_{2}$ receptors, releases CYP-AA metabolites which mediate renal vasodilation. In the present study, the effect of AngII on renal vascular circulation under $\mathrm{AT}_{1}$ receptor blockade in the presence of CYP-AA inhibitors was explored.

\section{Methods}

Male Sprague-Dawley (300-350 g) rats were used. Renal vascular tone was evaluated in the isolated perfused kidney of the rat according to methods previously described [5]. Various doses of AngII (1 2, 5 and $16 \mathrm{ng}$ ) were administered randomly as a bolus, with each successive dose administered when perfusion pressure had returned to the basal value. After establishing the control response, the kidneys were then perfused with the $\mathrm{AT}_{1}$ receptor antagonist Losartan (2n-butyl-4-chloro-5-hydroxymethyl-1[2'-(1H-tetrazol-5-yl)biphenyl4-yl)methyl]imidazole, $(1 \mu M)$, a generous gift from Merck Sharp and Dohme Mexico. Losartan $(1 \mu M)+$ the $\mathrm{AT}_{2}$ receptor antagonist CGP42112A (N- $\alpha$-nicotinoyl-Tyr-(N- $\alpha$-CB2-Arg)-Lys-His-Pro-Ile$\mathrm{OH}, 1 \mu M$, from RBI, Natick, Mass., USA), Losartan $(1 \mu M)+$ the cyclooxygenase inhibitor indomethacin $(1 \mu \mathrm{g} / \mathrm{ml}$, from St. Louis, Mo., USA), Losartan $(1 \mu M)+$ the AA antagonist ETYA (eicosatetraynoic acid ( $1 \mu M$, from Cayman, Ann Arbor, Mich., USA) and Losartan $(1 \mu M)+$ the cytochrome P-450 inhibitor clotrimazole ( $1 \mu M$, from St. Louis, Mo., USA) were used. Thirty minutes after initiation of the perfusion of the inhibitor, AngII (16 ng) was admin- istered into the perfusate line. The U46619 was used as a control for the specificity of the inhibitors and the time-dependent damage of the preparation.

\section{Results}

Administration of AngII increased renal perfusion pressure of isolated perfused kidneys of the rat in a dosedependent manner. The 1-, 2-, 5- and 16-ng doses of AngII increased the perfusion pressure to $27 \pm 10,41 \pm$ $10,54 \pm 18$ and $62 \pm 29 \mathrm{~mm} \mathrm{Hg}$, respectively. Losartan $(1 \mu M)$, an $\mathrm{AT}_{1}$ receptor antagonist, abolished the response elicited by AngII doses of 1, 2, and $5 \mathrm{ng}$. However, the highest dose of AngII used (16 ng) in the presence of Losartan in the perfusion solution unmasked a vasodilatory response. Thus, AngII decreased perfusion pressure by $15 \pm 3 \mathrm{~mm} \mathrm{Hg}$ (fig. 1). Moreover, the AngII-induced renal vasodilatory response was practically abolished when the AngII $\mathrm{AT}_{2}$ receptor blocker CGP $(1 \mu M)$ was added to the perfusion solution containing Losartan. Thus, CGP inhibited $90 \%$ of the AngII-induced renal vasodilation (fig. 1). The U46619 renal vascular effects were not affected by the presence of the inhibitor. Thus, U46619 increased perfusion pressure to $58 \pm 18,60 \pm 13$ and $61 \pm 10 \mathrm{~mm} \mathrm{Hg}$ in the absence and presence of Losartan or CGP, respectively. In order to characterize the participation of the AA metabolites on this AngIIinduced renal vasodilatory response, ETYA $(1 \mu M)$ which inhibits the activity of all oxygenases metabolizing AA, was used. The presence of this inhibitor decreased the AngII-induced renal vasodilatory response (fig. 1). However, inhibition of the cyclooxygenase activity with indomethacin $(1 \mu M)$ did not affect the AngII-induced renal vasodilation (fig. 1) whereas inhibition of the CYP-AA pathway with the inhibitor clotrimazole $(1 \mu M)$ practically abolished the AngII-induced renal vasodilatory response of the isolated perfused kidney of the rat (fig. 1). The vasoconstrictor effect of U46619 was not affected by either of the inhibitors used. The U46619 increased perfusion pressure to $58 \pm 18,63 \pm 2,57 \pm 5$ and $57 \pm$ $3 \mathrm{~mm} \mathrm{Hg}$ in the absence or presence of ETYA, indomethacin or clotrimazole, respectively.

\section{Discussion}

In the present study it has been demonstrated that under $\mathrm{AT}_{1}$ blockade, AngII produces a renal vasodilatory response. The results suggest that AngII renal vascular 
effects are the consequence of the activation of a vasoconstrictor and a vasodilator mechanism and that the balance between the two mechanisms represents the AngII-induced renal vascular response, suggesting that activation of $\mathrm{AT}_{2}$ receptors acts as a negative feedback mechanism to regulate AngII-induced vasoconstrictor effects [5]. Having demonstrated the presence of functional $\mathrm{AT}_{2}$ receptors in the renal circulation, we sought to clarify the mechanism of AngII-induced renal vasodilation. Blockade of the AA metabolism with ETYA prevented the renal vasodilatory response to AngII, suggesting that the AngII effect could be mediated by an AA metabolite [6]. The lack of effect and the prevention of the AngII effect by the cyclooxygenase inhibitor and the CYP inhibitor, respectively, suggest that a CYP-AA metabolite may be responsible for the AngII-induced renal vasodilation. There are conflicting data from previous reports regarding the role of cyclooxygenase products as mediators of the $\mathrm{AT}_{2}-$ dependent vasodepressor responses [7] and whether CYP-AA metabolites could be the mediators of AngII dilation of the afferent arteriole [3]. Although we did not explore the possibility that there is an AngII metabolism to its different fragments, the fact that in the presence of AA metabolism inhibitors, the AngII-induced vasodilatory response was prevented suggests that the AngII metabolism is not involved in the mechanism of the AngIIinduced renal vasodilation.

\section{Conclusion}

The findings indicate that in the renal circulation there are $\mathrm{AT}_{1}$ and $\mathrm{AT}_{2}$ receptors mediating the vascular effects of AngII, and that activation of $\mathrm{AT}_{2}$ receptors could mediate vasodilation through CYP-AA metabolism.

\section{References}

1 Viswanathan M, Tsutsumi K, Correa FMA, Saavedra JM: Changes in expression of angiotensin receptor subtypes in the aorta during development. Biochem Biophys Res Commun 1991;170:1361-1367.

2 Arima S, Endo Y, Yaoita H, Omata K, Ogawa S, Tsunoda K, Abe M, Takeuchi K, Abe K, Ito S: Possible role of P-450 metabolite arachidonic acid in vasodilator mechanism of angiotensin II type 2 receptor in the isolated microperfused rabbit afferent arteriole. J Clin Invest 1997;100:2816-2823.
3 Jacobs S, Douglas J: Angiotensin II type 2 receptor subtype mediates phospholipase A2dependent signaling in rabbit tubular epithelial cells. Hypertension 1993;28:663-668.

4 Navar G, Incho W, Majid S, Imig J, HarrisonBernard L, Mitchel M: Paracrine regulation of the renal microcirculation. Physiol Rev 1992; 76:425-536.

5 Sanchez-Mendoza, Hong E, Escalante B: The role of nitric oxide in angiotensin II-induced renal vasoconstriction in renovascular hypertension. J Hypertens 1998;16:697-703.
6 Harder R, Cambell B, Roman R: Role of cytochrome P-450 enzymes and metabolites of arachidonic acid in the control of vascular tone. $\mathrm{J}$ Vasc Res 1995;32:79-92.

7 Israel A, Cierco M, Sosa B: Angiotensin AT2 receptor mediates vasodepressor response to footshock in rats: Role of kinins, nitric oxide and prostaglandins. Eur J Pharmacol 2000; 394:103-108. 